\title{
Regulatory B cells in infectious disease (Review)
}

\author{
YOU-CHAO DAI ${ }^{1,2}$, JIXIN ZHONG ${ }^{3}$ and JUN-FA XU ${ }^{1,2}$ \\ ${ }^{1}$ Guangdong Provincial Key Laboratory of Medical Molecular Diagnostics; ${ }^{2}$ Department of Clinical Immunology, \\ Institute of Laboratory Medicine, Guangdong Medical College, Dongguan, Guangdong 523808, P.R. China; \\ ${ }^{3}$ Department of Medicine, University of Maryland School of Medicine, Baltimore, MD 21201, USA
}

Received April 12, 2016; Accepted March 22, 2017

DOI: $10.3892 / \mathrm{mmr} .2017 .6605$

\begin{abstract}
Regulatory B cells (Bregs) are a subset of B cells, which reportedly exert significant immunomodulatory effects through the production of interleukin (IL)-10, IL-35 and transforming growth factor- $\beta$. Over the last decade, studies have indicated that Bregs function in autoimmune and allergic diseases through antigen-specific and non-specific immunoregulatory mechanisms. However, only a limited number of reviews have focused on the role of Bregs during infection, particularly their functions in intracellular infections. The present review discusses the role of Bregs in infectious diseases in animal models and human studies, and provides an overview of the immunoregulatory mechanisms used by Bregs.
\end{abstract}

\section{Contents}

1. Introduction

2. Breg phenotypes

3. Immunomodulation by Bregs

4. Bregs in infections

5. Conclusion

Correspondence to: Professor Jun-Fa Xu, Guangdong Provincial Key Laboratory of Medical Molecular Diagnostics, 1 Xincheng Road, Dongguan, Guangdong 523808, P.R. China

E-mail: xujunfa@gdmc.edu.cn; imxujunfa@163.com

Abbreviations: IL, interleukin; TGF- $\beta$, transforming growth factor- $\beta$; B10, IL-10-producing B cell; Breg, regulatory B cell; Treg, regulatory T cell; DC, dendritic cell; EAE, experimental autoimmune encephalomyelitis; PBMC, peripheral blood mononuclear cell; TLR, Toll-like receptor; BCR, B cell receptor; Th, T helper cell; IFN, interferon; CTL, cytotoxic T lymphocyte; Ebi3, Epstein-Barr virus-induced gene 3; STAT, signal transducer and activator of transcription; GraB, granzyme B-expressing B cell; MHC, major histocompatibility complex; HIV, human immunodeficiency virus; PD, programmed death; LAP, latency-associated peptide; TB, tuberculosis; Ig, immunoglobulin

Key words: regulatory B cells, interleukin-10, interleukin-35, infections, immune modulation

\section{Introduction}

B lymphocytes, also known as B cells, are well known for their ability to mediate the humoral immune response by differentiating into antibody-secreting cells. In previous years, a novel subset of B cells, which exert immunomodulatory effects through the production of interleukin (IL)-10 and transforming growth factor- $\beta$ (TGF- $\beta$ ) have been identified and classified as regulatory B cells (Bregs). To date, Bregs have been described in a number of reports (1-3), some of which refer to Bregs as IL-10-producing B cells or B10/Br1 cells $(4,5)$. The role of IL-10-producing B cells was first demonstrated in a murine model of chronic intestinal inflammation (6), however, Bregs have also been reported to function in autoimmune diseases (7), allergic diseases $(8,9)$, graft-versus-host disease $(10,11)$ and cancer (12) through antigen-specific and non-specific immunoregulatory mechanisms. Previously, a novel subset of Bregs possessing a plasma cell phenotype, which expresses CD138 and produces anti-inflammatory IL-10 and IL-35 cytokines during Salmonella infections and experimental autoimmune encephalomyelitis (EAE) was reported. Accordingly, studies investigating Bregs have become more extensive $(13,14)$.

A previous report described a naturally occurring subset of Bregs, which facilitated the maintenance of homeostasis within adipose tissue and suggested that Breg cell dysfunction may be pivotal in the progression of adipose tissue inflammation in obesity (14). However, corresponding data on the role of Bregs during infection, particularly their functions during intracellular infections, are limited. The present review aimed to discuss the role of Bregs in various infections and attempt to uncover potential markers or valuable targets for the development of therapeutic interventions for the treatment of infectious diseases.

\section{Breg phenotypes}

Although several potential markers for Bregs have been described, the unequivocal identification of Bregs in infectious disease has not been achieved. In mice, the most widely accepted Breg subsets are $\mathrm{CD} 19^{+} \mathrm{CD} 5^{+} \mathrm{CD} 1 \mathrm{~d}^{\text {hi }}$ Bregs $(5,15,16)$ and $\mathrm{CD} 19^{+} \mathrm{CD} 21^{+} \mathrm{CD} 23^{+}$Bregs $(15,17)$. However, controversy remains over the identification of Bregs in mice. A subset of Bregs possessing a $\mathrm{CD} 138^{+}$plasma cell phenotype were previously reported to produce IL-10 and IL-35 during Salmonella infection in mice (18). In addition, Wilson et al reported the 
identification of a population of Bregs expressing high levels of CD23 in the absence of CD5 and CD1d in the mesenteric lymph nodes of helminth-infected mice (19).

In humans, reports of the identification of Bregs are more diverse. Generally, the established Breg subsets in humans include $\mathrm{CD} 19^{+} \mathrm{CD} 24^{+} \mathrm{CD} 38^{+}$Bregs $(1,2,20,21)$ and $\mathrm{CD} 19^{+} \mathrm{CD} 24^{+} \mathrm{CD} 27^{+}$Bregs (22), although reports have also included the identification of $\mathrm{CD} 19^{+} \mathrm{CD}^{+}{ }^{+} \mathrm{CD} 1 \mathrm{~d}^{+}$Bregs $(23,24)$ and CD19+TIM-1 ${ }^{+}$Bregs (17) in humans. However, certain phenotypes are not supported by evidence in human immunodeficiency virus (HIV)-infected individuals, which suggests human 'Bregs' lacking the expression of CD1d may not be Bregs.

Multiple Breg cell surface markers have been reported, a number of which have been identified in humans and mice (Fig. 1). However, discrepancies in the phenotypes reported across studies are apparent. These differences are most likely due to the use of an imperfect panel of markers to characterize the B cell subsets, different disease models and organic sources, and the use of different induction methods, including Toll-like receptor (TLR) ligands or CD40 and B cell receptor (BCR) agonists, all of which can affect phenotype (Table I).

\section{Immunomodulation by Bregs}

Although the regulatory mechanism of Bregs in infectious disease remains to be fully elucidated, data from multiple studies have indicated that a diverse array of immunomodulatory cytokines follow the emergence of Bregs, of which IL-10 is the most frequently investigated. Although IL-10 is produced by various cell types and exhibits several pleiotropic effects, the expression of IL-10 by human and mouse Bregs is central to their negative regulation of adaptive and innate immune responses $(1-3,5,15,20,22,25)$.

The differentiation of $\mathrm{T}$ cells into $\mathrm{T}$ helper cells (Th), including Th1, Th2 and Th17 cells, all of which possess a protective capacity during infection, can be inhibited by IL-10 (23-27), as shown in Fig. 2. In other circumstances, IL-10 can suppress the secretion of IL-22, IL-17 and interferon- $\gamma$ (IFN- $\gamma$ ) by $\mathrm{CD}^{+} \mathrm{T}$ cells $(3,21,23,24,28)$. In addition, IL-10 can attenuate the differentiation of $\mathrm{CD} 8^{+} \mathrm{T}$ cells into cytotoxic $\mathrm{T}$ lymphocytes (CTLs) under certain stimuli. Breg depletion in vitro leads to enhanced CTL activity in $\mathrm{CD} 8{ }^{+} \mathrm{T}$ cells, whereas activated Bregs may contribute to the attenuation of CTL functions $(2,22,29)$ (Fig. 2). Other reports have indicated that increased numbers of Bregs potentially contribute to elevated levels of IL-10 and induce forkhead box P3 (FOXP3) ${ }^{+}$regulatory $\mathrm{T}$ cells (Tregs), which exhibit broader suppressive functions $(1,16)$.

Following TLR activation, innate $\mathrm{CD}^{+}$Bregs are able to suppress dendritic cell (DC) IL-12 secretion by producing high levels of IL-10 $(15,30)$. In a separate study, Qian et al demonstrated that regulatory DCs can induce splenic B cells to differentiate into a distinct subtype of IL-10-producing Bregs with a unique $\mathrm{CD} 19^{\text {hi }} \mathrm{Fc} \gamma \mathrm{IIb}^{\text {hi }}$ phenotype (31). Other reports have indicated that Bregs produce the immunomodulatory cytokine, TGF- $\beta$, in allergic $(9,32,33)$ and infectious $(3,34)$ diseases. Although the potential co-expression of TGF- $\beta$ and IL-10 remains to be fully elucidated, the expression of TGF- $\beta$ and IL-10 by different Breg subsets, and the presence of an increased percentage of $\mathrm{CD} 24^{\text {hi }} \mathrm{CD} 27^{+}$and $\mathrm{CD} 1 \mathrm{~d}^{\text {hi }} \mathrm{B}$ cells in Schistosoma-infected mice expressing TGF- $\beta$ and IL-10, respectively, has been determined (3). However, the distinct role of human TGF- $\beta$-expressing Bregs in infectious diseases requires elucidation.

A previous study revealed that B cells activated by TLR4 and CD40 can upregulate the expression of Epstein-Barr virus-induced gene 3 (Ebi3), also known as IL-27 $\beta$, and p35, also known as IL12a, which dimerize to generate IL-35 (18) (Table I). The development of Salmonella infection in mice lacking either the Ebi3 or the p35 subunit in B cells was found to be exacerbated, which indicated that IL-35 was essential for the suppressive functions of B cells. Wang et al (35) reported that IL-35 induced B cells and promoted their conversion into Breg subsets, which produced IL-35 and IL-10 by activating signal transducer and activator of transcription 1 (STAT1) and STAT3. However, whether the differential expression of IL-35 and IL-10 by these subsets was due to instructive or stochastic mechanisms remains to be elucidated. The increased expression of serine protease granzyme B ( $\mathrm{GraB}$ ) by a subset of Bregs, termed GraB cells, is another regulatory B cell mechanism, which weakens $\mathrm{T}$ cell responses (36).

In addition to the aforementioned secretory factors, Bregs are involved in pathophysiological processes by directly inhibiting autoreactive T cells and innate immune cells. Bregs can make contact with effector $\mathrm{T}$ cells through CD40/CD40L, which accelerates the process of $\mathrm{T}$ cell apoptosis (5). Previously, enhanced bacterial clearance in mice lacking IL-10-producing Bregs (B10 cells) was found to correspond with improved bacterial phagocytosis by macrophages, and to significant increases in the ex vivo production of IFN- $\gamma$, TNF- $\alpha$ and nitric oxide by macrophages $(5,23)$. The expression of major histocompatibility complex (MHC) class II molecules and CD21R by B10 cells supports the argument that $\mathrm{B} 10$ cells require cognate interactions with $\mathrm{CD} 4^{+} \mathrm{T}$ cells to induce their regulatory effector functions during infection. Therefore, macrophage function is likely to be regulated downstream of $\mathrm{B} 10$ cell interactions with $\mathrm{CD}^{+} \mathrm{T}$ cells $(5,25)$ (Fig. 2). Bregs have also been shown to represent a significant source of serum immunoglobulin (Ig)M and IgG during adoptive transfer experiments, and produce antigen-specific, polyreactive and autoreactive antibody (Ab) specificities (30). However, their antibody-mediated immune responses in infectious diseases remain to be fully elucidated.

\section{Bregs in infections}

Role of Bregs in viral infections. The effects of B cell-mediated humoral immunity on the clearance of intracellular infection are limited. Only a few studies have focused on the role of Bregs in intracellular infections, and investigation in viral infections has focused predominantly on the HIV and hepatitis B virus (HBV). The involvement of Bregs in viral infections is primarily through IL-10-mediated immunological effects. Das et al (22) provided the first demonstration that Bregs regulate antigen-specific $\mathrm{CD} 8^{+} \mathrm{T}$ cells in HBV infection. It was found that IL-10-producing B cells (25) and serum levels of IL-10 correlated with spontaneous flare-ups of liver disease in patients with chronic HBV infection (CHB), but not in patients with acute HBV 


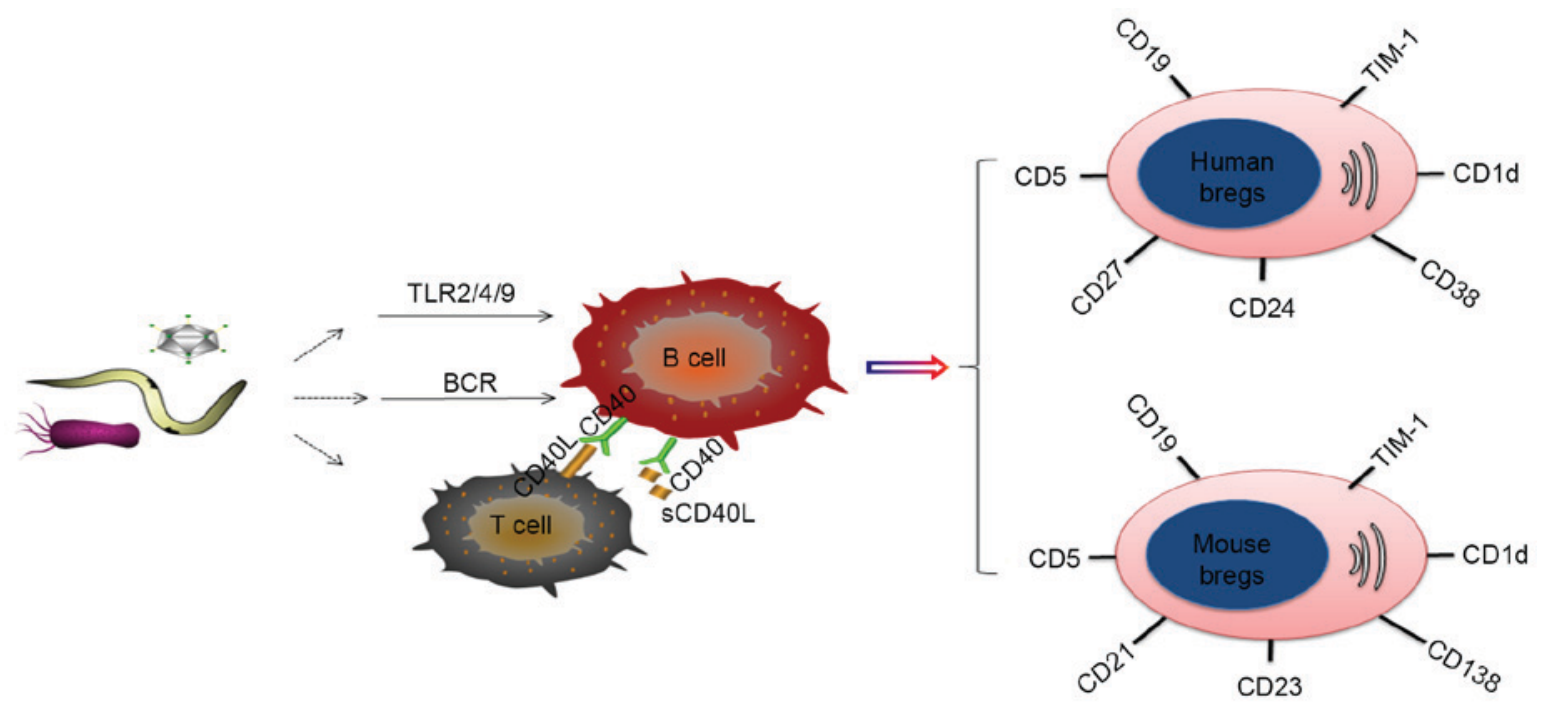

Figure 1. Signals for the development of Bregs in infectious disease. Following viral, parasitic or bacterial infection, Bregs can be activated via BCR and/or TLR cross-linking plus CD40 ligation. Typical Breg cell markers differ between humans and mice, however, partial overlap exists. Bregs, regulatory B cells; $\mathrm{BCR}, \mathrm{B}$ cell receptor; TLR, Toll-like receptor.

infection or in healthy subjects. In vitro, the inhibition of IL-10 may restore HBV-specific $\mathrm{CD}^{+} \mathrm{T}$ cell polyfunctionality (22). In addition Bregs contribute to increased levels of IL-10 in HVB non-responders and leads to an induction of suppressive FOXP3 ${ }^{+}$Tregs, which exert broader suppressive functions $(1,25)$ (Table I). In the absence of stimulation, IL-10-producing B cells predominantly exhibit an immature phenotype; however, these are the only B cell subset to correlate with hepatic flares (22) (Table I).

Previous studies have demonstrated that Bregs contribute to immune dysfunction associated with HIV infection through $\mathrm{T}$ cell impairment, specifically by the expression of IL-10 and possibly programmed death (PD)-L1, a member of the B7-H1 family. The suppressive properties of Bregs in HIV infection are associated with a systemic prevalence of TLR ligands and CD40L, as demonstrated by an in vitro experiment in which TLR2-, TLR9- and CD40L-costimulated Bregs from healthy controls led to increased expression of PD-L1 and a higher frequency of IL-10-positive cells (2). Although the percentage of $\mathrm{B} 10$ cells in the $\mathrm{CD} 19^{+} \mathrm{CD} 24^{\mathrm{hi}} \mathrm{CD} 38^{\mathrm{hi}} \mathrm{B}$ cell population is increased following ex vivo stimulation, a reduction in $\mathrm{CD} 19^{+} \mathrm{CD} 24^{\mathrm{hi}} \mathrm{CD} 38^{\mathrm{hi}} \mathrm{B}$ cell frequency has been reported in HIV-infected individuals. This may be due to the suppression of CTL functions by activated Bregs, which lead to viral persistence (2) (Table I). Ex vivo, the frequency of IL-10-producing B cells has been negatively associated with contemporaneous $\mathrm{T}$ cell responses, which supports the role of B10 cells in HIV-1-specific CD8 ${ }^{+}$T cell dysfunction (17).

A previous report indicated that $\mathrm{B}$ cells from untreated patients with HIV differentiated into Bregs overexpressing GraB when cultured with autologous IL-21 ${ }^{+}$CD 40 L Th cells. These GraB cells are distinct from traditional B10 cells, and exhibit increased expression levels of CD5, CD86, CD43 and CD147, but do not produce IL-10 (36) (Table I). A feedback mechanism has been identified in HIV-infected children whereby the increased circulating Bregs induced by robust humoral and cell-mediated immunity following vaccination may contribute to poor vaccine responses (37).
Compared with other diseases, CD1d is not a marker for Bregs in HIV infection (20), despite its apparent downregulation during HIV-1 infection (38). These observations may be explained by differences in the immune systems of infected individuals, or by the effects of HIV on Breg phenotypes. In addition, $\mathrm{CD} 19^{+} \mathrm{CD} 1 \mathrm{~d}^{\text {hi }} \mathrm{CD} 5^{+} \mathrm{B}$ cells have been reported to infiltrate the brain and control neuroinflammation in a chronic infection model, as evidenced by reduced $\mathrm{CD} 8^{+} \mathrm{T}$ cells $/$ microglial responses and enhanced accumulation of Tregs (29).

Although IL-10 likely originates from different cell types including T cells (39), macrophages (40), and natural killer cells (41), several reports have indicated that Bregs may be a primary source of IL-10 and that the production of IL-10 begins to increase in the early stage of infection in tandem with viral load $(22,25)$ (Table I). However, whether or not Bregs are in the primary source of IL-10 during host response to infection remains to be elucidated. Accordingly, current data are based on a 'relative depletion' model of IL-10-expressing cells, which means a certain level remains present in the system. Therefore, the possibility exists that other cell types are similarly responsible for the production of IL-10.

Role of Bregs in parasitic infections. Studies of allergic inflammation have demonstrated that chronic parasitic (protozoa and helminth) infections are often associated with a reduced prevalence of hyper-inflammatory responses, including allergies $(42,43)$. The prevalence of autoimmune disease inversely correlates with parasitic infections, and increasing evidence has shown that parasitic worm infection may protect against autoimmune conditions (44). ES-62, a molecule secreted by the parasitic filarial nematode Acanthocheilonema viteae, had therapeutic potential in the treatment of rheumatoid arthritis due to its properties associated with the restoration of IL-10-producing Bregs and reduced plasma cell infiltration in the joints (45). The induction of immune regulatory cells and soluble cytokines upon helminthic infection is important for understanding the control of autoimmunity and allergic inflammation. Until now, the majority of studies investigating 


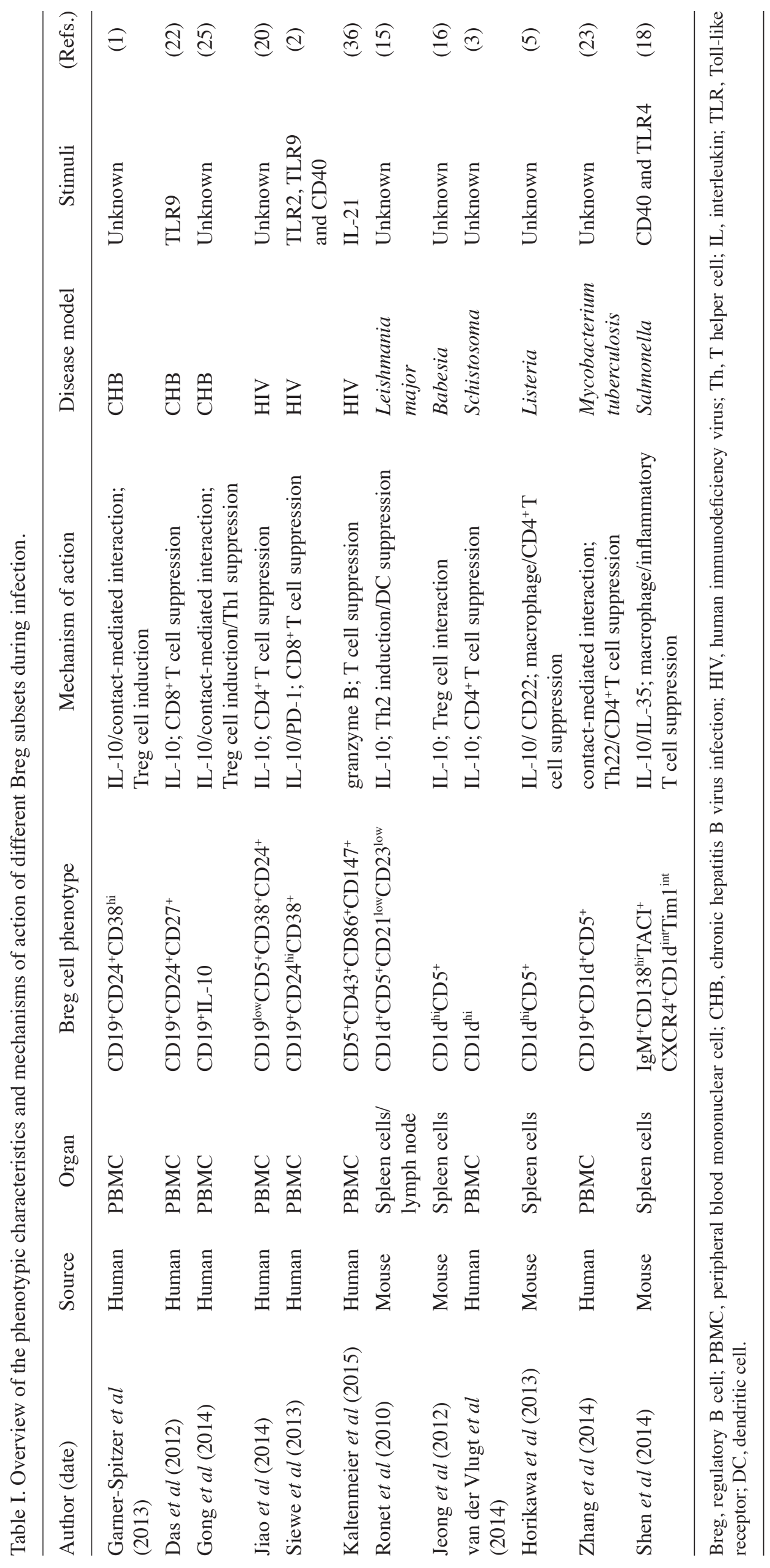




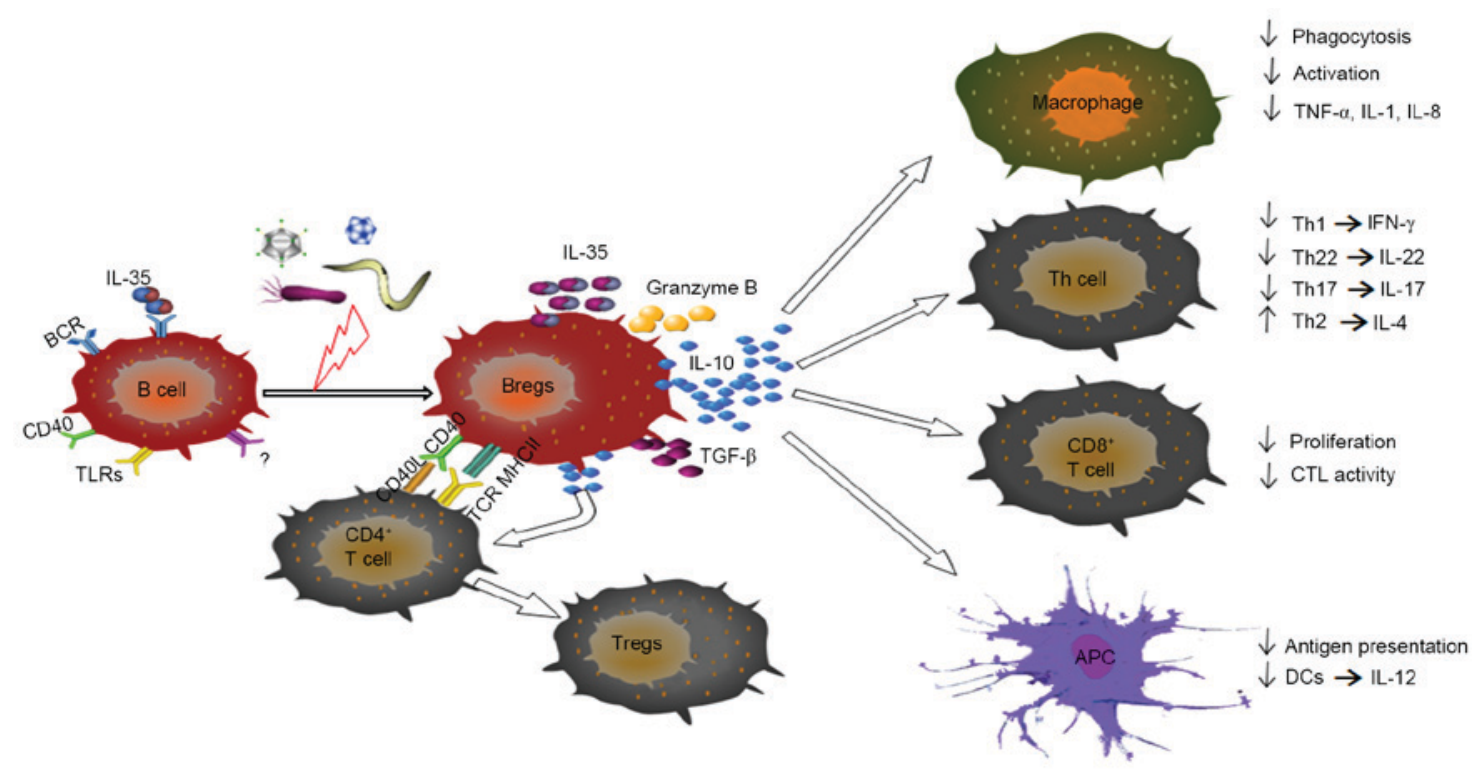

Figure 2. Immunomodulatory properties of Bregs during infectious disease. Through the contact-mediated interaction and/or secretion of IL-10, TGF- $\beta$, IL-35 or granzyme B, Bregs can suppress the activation and production of cytokines by pro-inflammatory lymphocytes, including macrophage, certain Th cells, CD8 ${ }^{+}$T cells and DCs. Bregs can also induce the differentiation of Th2 cells and Treg cells, primarily through IL-10. Breg, regulatory B cell; Treg, regulatory T cell; Th, T helper; DCs, dendritic cells; APC antigen-presenting cell; BCR, B cell receptor; CTL, cytotoxic T lymphocyte; IL, interleukin; TGF- $\beta$, transforming growth factor- $\beta$; TLR, Toll-like receptor

Bregs in helminthic infection have involved adoptive transfer experiments and used alleviated disease symptoms and/or protection against disease development as read-outs for Breg activity (43).

The shift in Th1/Th2 balance triggered by infection induces the Th2 response, and likely leads to a concomitant suppression of the Th1 involved in different stages of parasite infections $(15,27,46)$. Th1 responses were found to be exaggerated in Schistosoma-infected B-cell-deficient mice, indicating that Schistosoma-induced B cells suppressed Th1 cells in wild-type mice (27). A previous study (15) also revealed that IL-10 produced by Bregs is required for susceptibility to Leishmania major LV39 infection in BALB/c mice and for polarization of the Th cell response toward the Th2 phenotype. This is consistent with a previous report that B cells from Schistosoma-infected mice secrete IL-10 and promote development of the Th2 immune response (46). In a separate study, B cells from patients with visceral Leishmaniasis exhibited enhanced ability to differentiate into B10 cells, which potently inhibited the activation, proliferation and cytokine secretion of $\mathrm{CD}^{+}{ }^{+} \mathrm{T}$ cells, compared with healthy controls (21). Following stimulation by Leishmania major, the IL-10 secreted by B cells also stems the production of IL-12 by DCs (15) (Table I). These IL-10-producing Bregs may be derived from existing circulating B cells or from progenitor Bregs following stimulation with CD40 ligand and/or BCR ligation for 2 days $(47,48)$. van der Vlugt et al found that, in Schistosoma-infected individuals, IL-10 and membrane-bound latency-associated peptide (LAP)/TGF- $\beta$ were predominantly expressed by the Breg subsets CD1d ${ }^{\text {hi }} \mathrm{B}$ cells and $\mathrm{CD} 24^{\text {hi }} \mathrm{CD} 27^{+} \mathrm{B}$ cells, respectively (3). However, the role of LAP/TGF- $\beta$ is not addressed in this review.

In addition to the production of secreted factors, Bregs are able to induce other suppressive cell types by contact-mediated interactions. When co-cultured with Breg cells from
Schistosoma-infected individuals, $\mathrm{CD} 4^{+} \mathrm{T}$ cells produced lower levels of IFN- $\gamma$, IL-4 and IL-17. By contrast, the conversion to $\mathrm{CD} 25^{\text {hi }} \mathrm{FoxP}^{+}$and IL- $10^{+} \mathrm{T}$ cells was enhanced $(3,28)$ (Table I).

Unlike trematode parasites, including Schistosoma, Babesia microti is a common protozoan parasite, which invades and replicates within erythrocytes. A previous study demonstrated that the adoptive transfer of Bregs enhanced susceptibility to protozoan parasite infection and suppressed allergic disease by inducing $\mathrm{CD} 4{ }^{+} \mathrm{CD} 25^{+} \mathrm{FoxP} 3^{+}$Tregs. These suppressive Tregs were not induced in the absence of $\mathrm{CD} \mathrm{d}^{\text {hi }} \mathrm{CD}^{+}{ }^{+}$Bregs (16). This was the first report on the expansion of Bregs following infection, suggesting that Babesia microti infection in mice may serve as a suitable model for investigating Bregs in helminthic infections (16). Although the involvement of Tregs in helminthic infections has been investigated extensively (42), only a limited number of studies have investigated the role of Bregs in helminthic infections. Thus, several questions remain, including whether or not the induction of Bregs and Tregs persists in chronic infections or following clearance of the parasite, and whether or not any other molecules secreted by the parasite have therapeutic potential in autoimmunity and allergic diseases.

Role of Bregs in bacterial infections. Pathogens utilize multiple mechanisms to manipulate Breg functions in order to modulate immune responses and evade host defenses. During intracellular Listeria infection (5), B10-mediated inhibition of bacterial clearance depends on the expression of IL-10, MHC class II molecules and CD21-R. This finding suggested that $\mathrm{B} 10$ cells require cognate interactions with $\mathrm{CD} 4^{+} \mathrm{T}$ cells to exert their regulatory functions, but not $\mathrm{CD} 8^{+} \mathrm{T}$ cells. By contrast, the depletion of Bregs using CD22 mAb substantially accelerated ex vivo bacterial clearance (92-97\% higher, compared with wild-type mice) as a result of significantly 
reduced $\mathrm{CD} 4^{+} \mathrm{T}$ cell expansion, enhanced macrophage phagocytosis, and enhanced production of IFN- $\gamma$, TNF- $\alpha$ and nitric oxide (Table I).

An earlier report (34) showed that B cell-deficient mice exhibited markedly enhanced resistance to the intracellular bacterium Brucella abortus, reflecting the importance of non-antibody-mediated B cell effector mechanisms. Similarly, the depletion of Bregs by CD20 mAb during disease initiation has been shown to enhance the severity of EAE (49). Previously, it was reported that antibiotic treatment induces a population of $\mathrm{CD}^{+}$Bregs in mice (50). However, another murine study demonstrated that intestinal dysbacteriosis imposed by antibiotic treatment inhibited the production of IL- $1 \beta$ and IL- 6 in DCs and macrophages, and reduced the number and function of Bregs (51).

In Mycobacterium tuberculosis infections, active tuberculosis (TB) has been directly associated with high frequencies of $\mathrm{CD}_{19}{ }^{+} \mathrm{CD}_{1}{ }^{+} \mathrm{CD}^{+}$Bregs, which exhibited higher suppressive activity and selectively inhibited Th17 cell activation by direct cell contact in the absence of IL-10. The inhibition of $\mathrm{CD} 4^{+} \mathrm{T}$ cells by $\mathrm{B}$ cells did not involve the induction of Tregs (24). Subsequent investigations by Zhang et al (23) revealed that successful anti-TB treatment in human TB induced an enhanced IL-22 response, an important cytokine in the immune response to Mycobacterium tuberculosis infection, by reducing the frequencies of $\mathrm{CD} 19^{+} \mathrm{CD} 5^{+} \mathrm{CD} 1 \mathrm{~d}^{+}$ Bregs. Of note, it was found that patients with cavitary TB, which is more severe than TB without cavitation, had significantly higher frequencies of $\mathrm{CD} 19^{+} \mathrm{CD} 1 \mathrm{~d}^{+} \mathrm{CD}^{+} \mathrm{B}$ cells. This finding suggested that Bregs impaired protective immunity and increased disease severity. In addition, the results of our previous study indicated that $\mathrm{CD} 19^{+} \mathrm{B}$ cells in patients with active TB expressed Ebi3 and IL-12p35, the subunits of IL-35 (data not published). Similar to IL-10, IL-35 is well known for its suppressive function in a several diseases $(18,35)$. According to a report by Shen et al, mice with a B-cell-restricted deficiency in p35 or Ebi3 exhibited higher survival rates, which were associated with increased macrophage and $\mathrm{CD}^{+} \mathrm{T}$ cell activation (18). However, further investigations are warranted to determine whether or not Bregs are a subset of IL-35-secreting $\mathrm{B}$ cells and to determine their exact role in immune regulation.

\section{Conclusion}

Bregs have emerged in the field of immune regulation and are critical in immune system balance (4). However, their indefinable phenotype, and the marked differences between humans and mice is a subject of debate. The identification and investigation of Bregs is complex as they do not demonstrate regulatory activity in situ, and can only be investigated following stimulation ex vivo. In addition, the concentration of Bregs is only $\sim 1-2 \%$ in PBMCs or the mouse spleen $(52,53)$. Despite this, Bregs are reported to have a distinctive role in infectious disease.

As previously described, increases in Bregs are positively correlated with viral and bacterial load, and can contribute to poor vaccine responses $(1,37)$. Bregs can also facilitate pathogen survival, particularly in early stages of infection, and subsequently cause increased disease severity by inhibiting inflammatory $\mathrm{T}$ cell and macrophage activation, primarily through the production of IL-10 $(5,22,25,34)$. In addition, Bregs afford protection against the hyper-inflammatory response in parasitic infections $(16,43,54)$, and an inverse correlation between the induction of B10 cells by parasites and the prevalence of autoimmune disease has been reported $(44,55)$.

In conclusion, the current review describes the role of Bregs in infectious disease in animal and human investigations. However, a comprehensive understanding of the regulatory mechanisms exerted by Bregs is required prior to exploiting novel therapies. It is possible that the inhibition or depletion of Bregs may assist in the clearance of intracellular pathogens and improve the efficiency of vaccines in chronic infection states. Following confirmation of Breg phenotypes and elucidation of their associated suppressive mechanisms, cell therapies aimed at treating allergic and autoimmune disease using autologous Bregs induced by in vitro parasite antigens may be possible in the future.

\section{Acknowledgements}

This study was supported by the National Natural Science Foundation of China (grant nos. 81273237, 81570009 and 30972779), the Natural Science Foundation of Guangdong Province (grant no. 2015A030313513), the Key Project of Science and Technology Innovation from Education Department of Guangdong Province (grant no. 2012KJCX0059), the Science and Technology Project of Dongguan (grant no. 201450715200503), the Science and Technology Project of Zhanjiang (grant no. 2013C03012) and the Science and Technology Innovation Fund of GDMC (grant nos. STIF201110 and B2012078).

\section{References}

1. Garner-Spitzer E, Wagner A, Paulke-Korinek M, Kollaritsch H, Heinz FX, Redlberger-Fritz M, Stiasny K, Fischer GF, Kundi M and Wiedermann U: Tick-borne encephalitis (TBE) and hepatitis B nonresponders feature different immunologic mechanisms in response to TBE and influenza vaccination with involvement of regulatory T and B cells and IL-10. J Immunol 191: 2426-2436, 2013.

2. Siewe B, Stapleton JT, Martinson J, Keshavarzian A, Kazmi N, Demarais PM, French AL and Landay A: Regulatory B cell frequency correlates with markers of HIV disease progression and attenuates anti-HIV CD8 ${ }^{+} \mathrm{T}$ cell function in vitro. J Leukoc Biol 93: 811-818, 2013.

3. van der Vlugt LE, Zinsou JF, Ozir-Fazalalikhan A, Kremsner PG, Yazdanbakhsh M, Adegnika AA and Smits HH: Interleukin 10 (IL-10)-producing CD1dhi regulatory B cells from Schistosoma haematobium-infected individuals induce IL-10-positive T cells and suppress effector T-cell cytokines. J Infect Dis 210: 1207-1216, 2014.

4. Berthelot JM, Jamin C, Amrouche K, Le Goff B, Maugars Y and Youinou P: Regulatory B cells play a key role in immune system balance. Joint Bone Spine 80: 18-22, 2013.

5. Horikawa M, Weimer ET, DiLillo DJ, Venturi GM, Spolski R, Leonard WJ, Heise MT and Tedder TF: Regulatory B cell (B10 Cell) expansion during Listeria infection governs innate and cellular immune responses in mice. J Immunol 190: 1158-1168, 2013.

6. Mizoguchi A, Mizoguchi E, Takedatsu H, Blumberg RS and Bhan AK: Chronic intestinal inflammatory condition generates IL-10-producing regulatory B cell subset characterized by CD1d upregulation. Immunity 16: 219-230, 2002.

7. Saussine A, Tazi A, Feuillet S, Rybojad M, Juillard C, Bergeron A, Dessirier V, Bouhidel F, Janin A, Bensussan A, et al: Active chronic sarcoidosis is characterized by increased transitional blood B cells, increased IL-10-producing regulatory B cells and high BAFF levels. PLoS One 7: e43588, 2012. 
8. Lee SJ, Noh G and Lee JH: In vitro induction of allergen-specific interleukin-10-producing regulatory $\mathrm{B}$ cell responses by interferon- $\gamma$ in non-immunoglobulin E-mediated milk allergy. Allergy Asthma Immunol Res 5: 48-54, 2013.

9. Natarajan P, Singh A, McNamara JT, Secor ER Jr, Guernsey LA, Thrall RS and Schramm CM: Regulatory B cells from hilar lymph nodes of tolerant mice in a murine model of allergic airway disease are CD5+, express TGF- $\beta$, and co-localize with CD4+Foxp3+ T cells. Mucosal Immunol 5: 691-701, 2012.

10. Furuzawa-Carballeda J, Lima G, Simancas P, Ramos-Bello D, Simancas M, Bostock IC, Vilatobá M, Gabilondo B, Granados J, Morales-Buenrostro L, et al: Peripheral regulatory cells immunophenotyping in kidney transplant recipients with different clinical profiles: A cross-sectional study. J Transplant 2012: 256960, 2012.

11. Lee KM, Kim JI, Stott R, Soohoo J, O'Connor MR, Yeh $\mathrm{H}$, Zhao $\mathrm{G}$, Eliades $\mathrm{P}$, Fox $\mathrm{C}$, Cheng $\mathrm{N}$, et al: Anti-CD45RB/anti-TIM-1-induced tolerance requires regulatory B cells. Am J Transplant 12: 2072-2078, 2012.

12. Chen T, Song D, Min Z, Wang X, Gu Y, Wei B, Yao J, Chen K, Jiang Z, Xie H, et al: Perioperative dynamic alterations in peripheral regulatory $\mathrm{T}$ and $\mathrm{B}$ cells in patients with hepatocellular carcinoma. J Transl Med 10: 14, 2012.

13. Giannoukakis $\mathrm{N}$ and Trucco $\mathrm{M}$ : A role for tolerogenic dendritic cell-induced B-regulatory cells in type 1 diabetes mellitus. Curr Opin Endocrinol Diabetes Obes 19: 279-287, 2012.

14. Nishimura S, Manabe I, Takaki S, Nagasaki M, Otsu M, Yamashita H, Sugita J, Yoshimura K, Eto K, Komuro I, et al: Adipose natural regulatory $\mathrm{B}$ cells negatively control adipose tissue inflammation. Cell Metab: Oct 22, 2013 (Epub ahead of print).

15. Ronet C, Hauyon-La Torre Y, Revaz-Breton M, Mastelic B, Tacchini-Cottier F, Louis J and Launois P: Regulatory B cells shape the development of Th2 immune responses in BALB/c mice infected with Leishmania major through IL-10 production. J Immunol 184: 886-894, 2010.

16. Jeong YI, Hong SH, Cho SH, Lee WJ and Lee SE: Induction of IL-10-producing CD1dhighCD5+ regulatory B cells following Babesia microti-infection. PLoS One 7: e46553, 2012.

17. Liu J, Zhan W, Kim CJ, Clayton K, Zhao H, Lee E, Cao JC, Ziegler B, Gregor A, Yue FY, et al: IL-10-producing B cells are induced early in HIV-1 infection and suppress HIV-1-specific T cell responses. PLoS One 9: e89236, 2014.

18. Shen P, Roch T, Lampropoulou V, O'Connor RA, Stervbo U, Hilgenberg E, Ries S, Dang VD, Jaimes Y, Daridon C, et al IL-35-producing B cells are critical regulators of immunity during autoimmune and infectious diseases. Nature 507: 366-370, 2014.

19. Wilson MS, Taylor MD, O'Gorman MT, Balic A, Barr TA, Filbey K, Anderton SM and Maizels RM: Helminth-induced CD19+CD23hi B cells modulate experimental allergic and autoimmune inflammation. Eur J Immunol 40: 1682-1696, 2010.

20. Jiao Y, Wang X, Zhang T, Sun L, Wang R, Li W, Ji Y, Wu H and Liu C: Regulatory B cells correlate with HIV disease progression. Microbiol Immunol 58: 449-455, 2014.

21. Andreani G, Ouellet M, Menasria R, Gomez AM, Barat C and Tremblay MJ: Leishmania infantum amastigotes trigger a subpopulation of human B cells with an immunoregulatory phenotype. PLoS Negl Trop Dis 9: e0003543, 2015.

22. Das A, Ellis G, Pallant C, Lopes AR, Khanna P, Peppa D, Chen A, Blair P, Dusheiko G, Gill U, et al: IL-10-producing regulatory $\mathrm{B}$ cells in the pathogenesis of chronic hepatitis B virus infection. J Immunol 189: 3925-3935, 2012.

23. Zhang M, Zeng G, Yang Q, Zhang J, Zhu X, Chen Q, Suthakaran P, Zhang Y, Deng Q, Liu H, et al: Anti-tuberculosis treatment enhances the production of IL-22 through reducing the frequencies of regulatory B cell. Tuberculosis (Edinb) 94 238-244, 2014

24. Zhang M, Zheng X, Zhang J, Zhu Y, Zhu X, Liu H, Zeng M, Graner MW, Zhou B and Chen X: CD19(+)CD1d(+)CD5(+) B cell frequencies are increased in patients with tuberculosis and suppress Th17 responses. Cell Immunol 274: 89-97, 2012.

25. Gong Y, Zhao C, Zhao P, Wang M, Zhou G, Han F, Cui Y, Qian J, Zhang $\mathrm{H}$, Xiong $\mathrm{H}$, et al: Role of IL-10-producing regulatory B cells in chronic hepatitis B virus infection. Dig Dis Sci 60 1308-1314, 2015

26. Flores-Borja F, Bosma A, Ng D, Reddy V, Ehrenstein MR, Isenberg DA and Mauri C: CD19+CD24hiCD38hi B cells maintain regulatory T cells while limiting TH1 and TH17 differentiation. Sci Transl Med 5: 173ra123, 2013.
27. Amu S, Saunders SP, Kronenberg M, Mangan NE, Atzberger A and Fallon PG: Regulatory B cells prevent and reverse allergic airway inflammation via FoxP3-positive $\mathrm{T}$ regulatory cells in a murine model. J Allergy Clin Immunol 125: 1114-1124.e8, 2010

28. Tian F, Hu X, Xian K, Zong D, Liu H, Wei H, Yang W and Qian L: B10 cells induced by Schistosoma japonicum soluble egg antigens modulated regulatory $\mathrm{T}$ cells and cytokine production of T cells. Parasitol Res 114: 3827-3834, 2015.

29. Mutnal MB, Hu S, Schachtele SJ and Lokensgard JR: Infiltrating regulatory $\mathrm{B}$ cells control neuroinflammation following viral brain infection. J Immunol 193: 6070-6080, 2014.

30. Lo-Man R: Regulatory B cells control dendritic cell functions. Immunotherapy 3 (4 Suppl): S19-S20, 2011

31. Qian L, Qian C, Chen Y, Bai Y, Bao Y, Lu L and Cao X: Regulatory dendritic cells program B cells to differentiate into CD19hiFc $\gamma$ IIbhi regulatory B cells through IFN- $\beta$ and CD40L. Blood 120: 581-591, 2012.

32. Lee JH, Noh J, Noh G, Choi WS, Cho S and Lee SS: Allergen-specific transforming growth factor- $\beta$-producing $\mathrm{CD} 19+\mathrm{CD} 5+$ regulatory $\mathrm{B}$-cell $(\mathrm{Br} 3)$ responses in human late eczematous allergic reactions to cow's milk. J Interferon Cytokine Res 31: 441-449, 2011.

33. Kessel A, Haj T, Peri R, Snir A, Melamed D, Sabo E and Toubi E: Human CD19(+)CD25(high) B regulatory cells suppress proliferation of CD4(+) T cells and enhance Foxp3 and CTLA-4 expression in T-regulatory cells. Autoimmun Rev 11: 670-677, 2012.

34. Goenka R, Parent MA, Elzer PH and Baldwin CL: B cell-deficient mice display markedly enhanced resistance to the intracellular bacterium Brucella abortus. J Infect Dis 203: 1136-1146, 2011.

35. Wang RX, Yu CR, Dambuza IM, Mahdi RM, Dolinska MB, Sergeev YV, Wingfield PT, Kim SH and Egwuagu CE: Interleukin-35 induces regulatory B cells that suppress autoimmune disease. Nat Med 20: 633-641, 2014.

36. Kaltenmeier C, Gawanbacht A, Beyer T, Lindner S, Trzaska T, van der Merwe JA, Härter G, Grüner B, Fabricius D, Lotfi R, et al: CD4+ T cell-derived IL-21 and deprivation of CD40 signaling favor the in vivo development of granzyme B-expressing regulatory B cells in HIV patients. J Immunol 194: 3768-3777, 2015.

37. Weinberg A, Muresan P, Fenton T, Richardson K, Dominguez T, Bloom A, Petzold E, Anthony $\mathrm{P}$, Cunningham CK, Spector SA, et al: High proportions of regulatory $\mathrm{B}$ and $\mathrm{T}$ cells are associated with decreased cellular responses to $\mathrm{pH} 1 \mathrm{~N} 1 \mathrm{influ}-$ enza vaccine in HIV-infected children and youth (IMPAACT P1088). Hum Vaccin Immunother 9: 957-968, 2013.

38. Leonard JA,FilzenT,CarterCC,SchaeferMandCollins KL:HIV-1 Nef disrupts intracellular trafficking of major histocompatibility complex class I, CD4, CD8, and CD28 by distinct pathways that share common elements. J Virol 85: 6867-6881, 2011.

39. Belkaid Y, Hoffmann KF, Mendez S, Kamhawi S, Udey MC, Wynn TA and Sacks DL: The role of interleukin (IL)-10 in the persistence of Leishmania major in the skin after healing and the therapeutic potential of anti-IL-10 receptor antibody for sterile cure. J Exp Med 194: 1497-1506, 2001

40. Pistoia V: Production of cytokines by human B cells in health and disease. Immunol Today 18: 343-350, 1997.

41. Maroof A, Beattie L, Zubairi S, Svensson M, Stager S and Kaye PM: Posttranscriptional regulation of II10 gene expression allows natural killer cells to express immunoregulatory function. Immunity 29: 295-305, 2008.

42. Jeong YI, Kim SH, Ju JW, Cho SH, Lee WJ, Park JW, Park YM and Lee SE: Clonorchis sinensis-derived total protein attenuates airway inflammation in murine asthma model by inducing regulatory $\mathrm{T}$ cells and modulating dendritic cell functions. Biochem Biophys Res Commun 407: 793-800, 2011.

43. Hussaarts L, van der Vlugt LE, Yazdanbakhsh M and Smits HH: Regulatory B-cell induction by helminths: Implications for allergic disease. J Allergy Clin Immunol 128: 733-739, 2011.

44. Rodgers DT, Pineda MA, McGrath MA, Al-Riyami L, Harnett W and Harnett MM: Protection against collagen-induced arthritis in mice afforded by the parasitic worm product, ES-62, is associated with restoration of the levels of interleukin-10-producing $B$ cells and reduced plasma cell infiltration of the joints. Immunology 141: 457-466, 2014

45. Pineda MA, McGrath MA, Smith PC, Al-Riyami L, Rzepecka J, Gracie JA, Harnett W and Harnett MM: The parasitic helminth product ES-62 suppresses pathogenesis in collagen-induced arthritis by targeting of the interleukin-17-producing cellular network at multiple sites. Arthritis Rheum 64: 3168-3178, 2012. 
46. Hernandez HJ, Wang Y and Stadecker MJ: In infection with Schistosoma mansoni, B cells are required for T helper type 2 cell responses but not for granuloma formation. J Immunol 158: 4832-4837, 1997.

47. Iwata Y, Matsushita T, Horikawa M, Dilillo DJ, Yanaba K, Venturi GM, Szaboles PM, Bernstein SH, Magro CM, Williams AD, et al: Characterization of a rare IL-10-competent B-cell subset in humans that parallels mouse regulatory B10 cells. Blood 117: 530-541, 2011.

48. DiLillo DJ, Matsushita T and Tedder TF: B10 cells and regulatory B cells balance immune responses during inflammation, autoimmunity, and cancer. Ann N Y Acad Sci 1183: 38-57, 2010.

49. Matsushita T, Horikawa M, Iwata Y and Tedder TF: Regulatory $\mathrm{B}$ cells (B10 cells) and regulatory T cells have independent roles in controlling experimental autoimmune encephalomyelitis initiation and late-phase immunopathogenesis. J Immunol 185: 2240-2252, 2010.

50. Ochoa-Reparaz J, Mielcarz DW, Haque-Begum S and Kasper LH: Induction of a regulatory B cell population in experimenta allergic encephalomyelitis by alteration of the gut commensal microflora. Gut Microbes 1: 103-108, 2010.
51. Rosser EC, Oleinika K, Tonon S, Doyle R, Bosma A, Carter NA, Harris KA, Jones SA, Klein N and Mauri C: Regulatory B cells are induced by gut microbiota-driven interleukin-1 $\beta$ and interleukin-6 production. Nat Med 20: 1334-1339, 2014.

52. Yanaba K, Bouaziz JD, Matsushita T, Magro CM, St Clair EW and Tedder TF: B-lymphocyte contributions to human autoimmune disease. Immunol Rev 223: 284-299, 2008.

53. Yanaba K, Bouaziz JD, Haas KM, Poe JC, Fujimoto M and Tedder TF: A regulatory B cell subset with a unique CD1dhiCD5+ phenotype controls $\mathrm{T}$ cell-dependent inflammatory responses. Immunity 28: 639-650, 2008.

54. Tang H, Ming Z, Liu R, Xiong T, Grevelding CG, Dong H and Jiang M: Development of adult worms and granulomatous pathology are collectively regulated by T- and B-cells in mice infected with Schistosoma japonicum. PLoS One 8: e54432, 2013.

55. Panda AK, Ravindran B and Das BK: Rheumatoid arthritis patients are free of filarial infection in an area where filariasis is endemic: Comment on the article by Pineda et al. Arthritis Rheum 65: 1402-1403, 2013. 